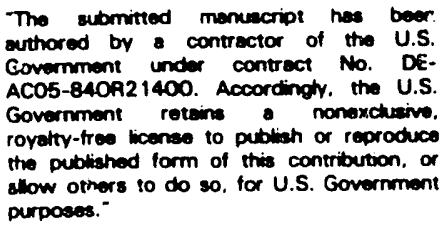

CONF-9.10617--7

DE92 003553

\title{
FABRICATION AND TESTING OF CORROSION RESISTANT COATINGS
}

\author{
D. P. STINTON, J. C. MCLAUGHLIN, and L. RIESTER \\ Oak Ridge National Laboratory \\ P.O. Box 2008, Oak Ridge, Tennessee 37831-6063 USA
}

\begin{abstract}
The susceptibility of $\mathrm{SiC}$ and $\mathrm{Si}_{3} \mathrm{~N}_{4}$ to sodium corrosion mandates that corrosion resistant coatings be developed to protect silicon-based turbine engine components. Materials with good corrosion resistance and thermal expansions that nearly match $\mathrm{SiC}$ and $\mathrm{Si}_{3} \mathrm{~N}_{4}$ have been identified. Corrosion testing of hot-pressed pellets of these compounds has identified the most promising materials. Development of chemical vapor deposition systems to apply these materials has been initiated.
\end{abstract}

\section{INTRODUCTION}

$\mathrm{SiC}$ and $\mathrm{Si}_{3} \mathrm{~N}_{4}$ are currently prime candidates for turbine engine applications because of their high retained strength to $1400^{\circ} \mathrm{C}$, excellent oxidation resistance, good thermal shock resistance, and light weight. Unfortunately, sodium, potassium, and steam have been shown to cause degradation of $\mathrm{SiC}$ and $\mathrm{Si}_{3} \mathrm{~N}_{4}$ at temperatures above $\approx 1200^{\circ} \mathrm{C}$.[1-4] However, corrosion has not been recognized as a significant problem in engine testing because current components can survive only several hundred hours due to thermal and mechanical stresses. After improved designs and materials permit tests of longer duration, the severity of the corrosion problem will become more evident.

The outer surfaces of $\mathrm{SiC}$ and $\mathrm{Si}_{3} \mathrm{~N}_{4}$ components oxidize at high temperatures to form a silica layer that inhibits further oxidation.[5] However, sodium ingested into turbine engines from the environment or impurities present in the fuel can react with this silica layer, such that it is no longer protective.[6,7] The primary corrosion mechanism is the formation of a sodium-silicate liquid phase at temperatures above $\approx 800^{\circ} \mathrm{C}$, the eutectic temperature in the sodium-silicate system.[8] The objective of the reported research is to develop a coating that will protect the $\mathrm{SiC}$ or $\mathrm{Si}_{3} \mathrm{~N}_{4}$ components or coatings from sodium corrosion as well as provide oxidation protection.

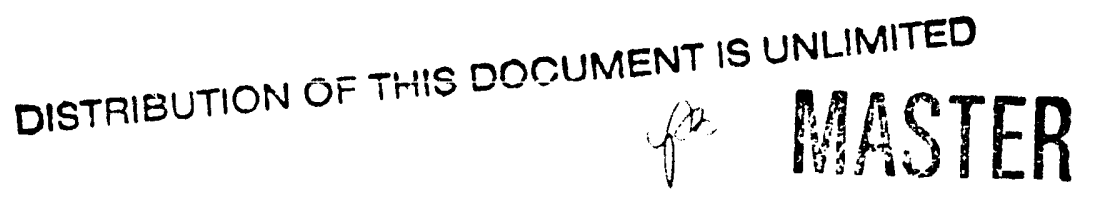




\section{BACKGROUND}

In 1986, GTE Laboratories initiated a program to develop coating systems to protect silicon-based ceramics from contact stress damage. Development of a protective coating for $\mathrm{SiC}$ or $\mathrm{Si}_{3} \mathrm{~N}_{4}$ is difficult because the coatings crack due to the mismatch in coefficient of thermal expansion (CTE) between the substrate (low CTE) and the coating (high CTE). A coating system was therefore designed to accommodate the stresses caused by the difference in CTE.[9] (Fig. 1) An AlN coating is initially deposited onto the SiC or $\mathrm{Si}_{3} \mathrm{~N}_{4}$ substrates to promote adherence via reaction (formation of a SiAlON compound) at the subs rate/coating interface. The coating is then compositionally graded from AlN to $\mathrm{Al}_{\mathrm{z}} \mathrm{O}_{\mathrm{y}} \mathrm{N}_{\mathrm{z}}$ to $\mathrm{Al}_{2} \mathrm{O}_{3}+\mathrm{ZrO}_{2}$. Residual stresses within the graded layer are minimized through the absence of sharp interfaces and the gradual increase in thermal expansion from the interface to the outer protective coating.

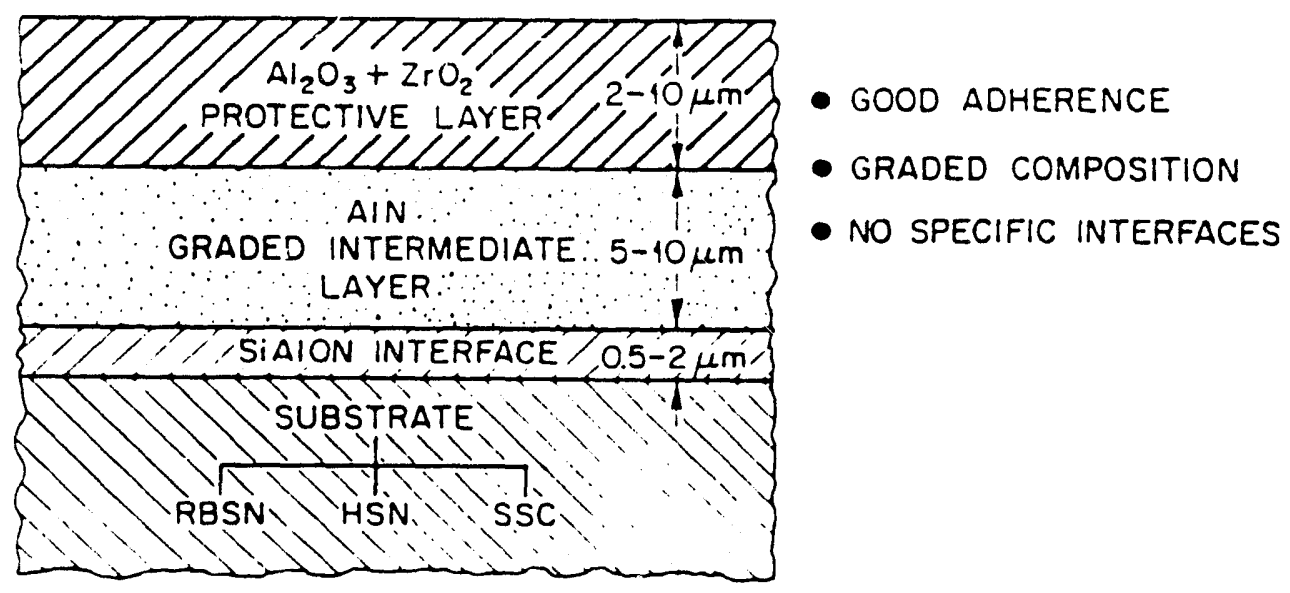

Figure 1. GTE's Protective Coating

The use of the GTE Laboratories' coating system appeared very promising for several years. $[10,11]$ Application of the coatings at about $1000^{\circ} \mathrm{C}$ produced adherent crack-free coatings. Repeated thermal cycling between room temperature and $\approx 1100^{\circ} \mathrm{C}$ produced no apparent effect on the coatings. However, heating the coatings to temperatures above $1200^{\circ} \mathrm{C}$ produced disastrous results, with the CTE mismatch causing the outer $\mathrm{Al}_{2} \mathrm{O}_{3}+\mathrm{ZrO}_{2}$ coating to crack. Penetration of oxygen through the cracks oxidized the AlN interfacial coating resulting in blistering of the outer coating. In an attempt to reduce the stresses at high temperatures, coatings were deposited at $1200^{\circ} \mathrm{C}$. However, these coatings spalled on cooling to room temperature. Developers of this coating system concluded that the difference in thermal expansion between $\mathrm{SiC}$ or $\mathrm{Si}_{3} \mathrm{~N}_{4}$ and $\mathrm{Al}_{2} \mathrm{O}_{3}+\mathrm{ZrO}_{2}$ is too great to develop an adherent, crack free coating. 


\section{CANDIDATE PROTECTIVE COATINGS}

The list of potential materials for corrosion protection of $\mathrm{SiC}$ and $\mathrm{Si}_{3} \mathrm{~N}_{4}$ is very limited because the material must be an oxide (for oxidation resistance) with a CTE significantly less than that of $\mathrm{Al}_{2} \mathrm{O}_{3}$ (for adherence). A carbon/carbon composite $(\mathrm{C} / \mathrm{C})$ is a material with a very low thermal expansion $(\approx 0)$ that must be protected from oxidation in hightemperature aerospace applications. However, after 20 years of investigation no oxidation resistant coatings have been found that can survive the dramatic thermal cycles, although several materials with low CTEs were identified that might be useful for the higher CTE heat engine components. (Table 1).

TABLE 1

Refractory Oxides with Potential for Oxidation/Corrosion Protection

\begin{tabular}{lcc} 
Compound & $\begin{array}{l}\text { Density } \\
\left(\mathrm{g} / \mathrm{cm}^{3}\right)\end{array}$ & $\begin{array}{c}\mathrm{CTE} \\
\left(\times 10^{-6} /{ }^{\circ} \mathrm{C}\right)\end{array}$ \\
\hline
\end{tabular}

\begin{tabular}{lcc}
$\mathrm{Al}_{2} \mathrm{O}_{3}{ }^{*}$ & 3.97 & 8.0 \\
$3 \mathrm{Al}_{2} \mathrm{O}_{3} \cdot 2 \mathrm{SiO}_{2}$ & 2.8 & 5.7 \\
$\mathrm{SiC}^{*}$ & 3.21 & 5.5 \\
$\mathrm{ZrTiO}_{4}$ & $\approx 5$ & $\approx 4$ \\
$\mathrm{HfTiO}_{4}$ & $\approx 5$ & $\approx 4$ \\
$\mathrm{Ta}_{2} \mathrm{O}_{5} \cdot 6 \mathrm{ZrO}_{2}$ & $\approx 6$ & $\approx 4$ \\
$\mathrm{Ta}_{2} \mathrm{O}_{5} \cdot 6 \mathrm{HfO}_{2}$ & $\approx 6$ & $\approx 4$ \\
$\mathrm{Ta}_{2} \mathrm{O}_{5}$ & 8.02 & 3.6 \\
$\mathrm{Si}_{3} \mathrm{~N}_{4}{ }^{*}$ & 3.19 & 3.0 \\
$\mathrm{Al}_{2} \mathrm{TiO}_{5}$ & 3.68 & 2.2 \\
carbon/carbon & 1.9 & $\approx 0$ \\
\hline
\end{tabular}

*Included only as a reference and not as a potential coating.

Mullite $\left(3 \mathrm{Al}_{2} \mathrm{O}_{3} \cdot 2 \mathrm{SiO}_{2}\right)$ is a material with a CTE very close to that of $\mathrm{SiC}$ and has performed reasonably well in corrosion tests, corroding somewhat more severely than $\mathrm{Al}_{2} \mathrm{O}_{3}$, but surviving significantly better than $\mathrm{SiC}$.[4] Corrosion resistance is dependent on the formation of stoichiometric mullite with no free $\mathrm{SiO}_{2}$, since free $\mathrm{SiO}_{2}$ is readily attacked. Because of its corrosion resistance and low CTE, mullite is also being investigated as a material for high-temperature particulate filters that are exposed to sodium contaminants.[12]

Not very much is known about the materials $\mathrm{ZrTiO}_{4}, \mathrm{HfTiO}_{4}, \mathrm{Ta}_{2} \mathrm{O}_{5} \bullet 6 \mathrm{ZrO}_{2}$, or $\mathrm{Ta}_{2} \mathrm{O}_{5} \bullet 6 \mathrm{HfO}_{2}$, however, investigations have shown their thermal expansions to be quite low.[13-15] The structures formed by the titanate phases provide significant advantages over the destructive phase transformations of monoclinic $\mathrm{ZrO}_{2}$ or $\mathrm{HfO}_{2}$. Stabilization of 
the cubic structure of $\mathrm{ZrO}_{2}$ with yttria, ceria, etc., is impractical because of their high thermal expansion $\left(13 \times 10^{-6} \% \mathrm{C}\right)$ and because the stabilizers would be leached out of the structure. $\mathrm{ZrTiO}_{4}$ and $\mathrm{HfTiO}_{4}$, however, crystallize in an orthorhombic structure that does not undergo polymorphic transformations.[16] (Fig. 2) Even less is known about $\mathrm{Ta}_{2} \mathrm{O}_{5} \bullet 6 \mathrm{ZrO}_{2}$ and $\mathrm{Ta}_{2} \mathrm{O}_{5} \bullet 6 \mathrm{HfO}_{2}$, although the reported[13] low thermal expansion and the potential for good corrosion resistance make the materials promising candidates.

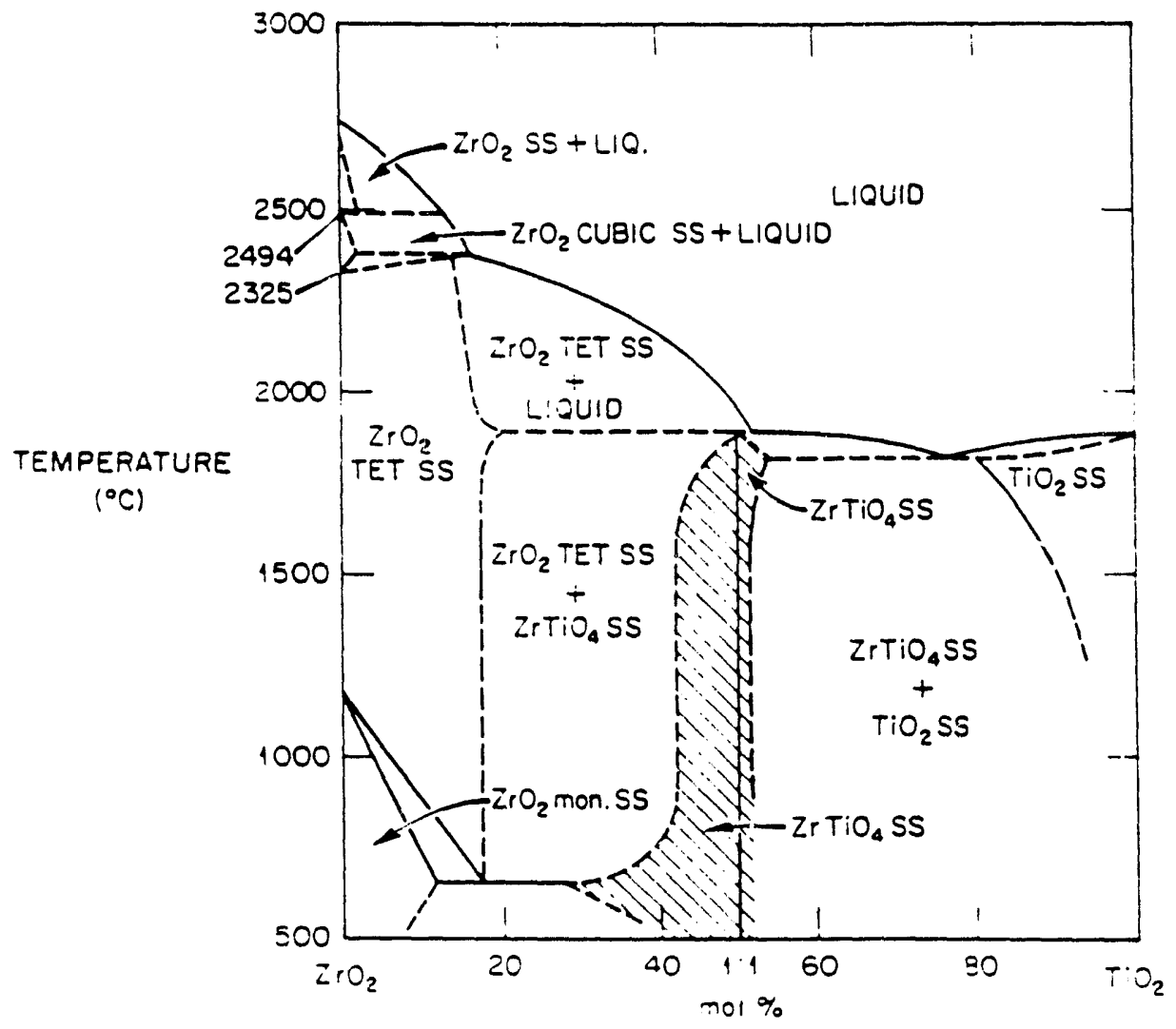

Figure 2. Phase equilibria in the $\mathrm{ZrO}_{2}-\mathrm{TiO}_{2}$ system.

An additional material of interest is $\mathrm{Ta}_{2} \mathrm{O}_{5}$, in part because of the ease of chemical vapor deposition.[17,18] Phase equilibria studies have shown that no liquid phases are present below $1625^{\circ} \mathrm{C}$.[19] Formation of either of the sodium tantalate phases at turbine application temperatures that are more than $300^{\circ} \mathrm{C}$ below the liquidus temperature would seem unlikely. Furthermore, the formation of these phases would not be catastrophic unless volume changes would cause spallation of the coatings.

One final material that shows promise is $\mathrm{Al}_{2} \mathrm{TiO}_{5}$ which has been investigated as a protective coating for $\mathrm{C} / \mathrm{C}$ and as a corrosion resistant material for high-temperature particulate filters.[20] However, obvious problems do exist for this material. First, because the CTE of the material is very anisotropic the material exhibits significant microcracking and could become permeable to oxygen and sodium. Second, the material tends to absorb water and could degrade significantly when exposed to an environment containing as little as $10 \%$ moisture at high temperatures. 
To adequately protect $\mathrm{SiC}$ and $\mathrm{Si}_{3} \mathrm{~N}_{4}$ components, the candidate protective coating must prevent oxygen present in the combustion environment from diffusing through the coatings to the substrate. Since oxygen will diffuse through most. oxide coatings at a significant rate, an additional barrier to oxygen must be established. The native $\mathrm{SiO}_{2}$ layer that coats $\mathrm{SiC}$ and $\mathrm{Si}_{3} \mathrm{~N}_{4}$ is impermeable to oxygen and prevents further oxidation; however, reaction with or diffusion into the corrosion resistant oxide coating would likely destroy the oxygen barrier. Therefore, testing will need to be performed to insure that the $\mathrm{SiO}_{2}$ layer is stable with respect to the candidate protective coatings.

\section{DESCRIPTION OF MATERIAIS AND EXPERIMENTS}

Development of processes to chemically vapor deposit all of the potential materials described above would be very costly and time consuming. Therefore, relatively easy to prepare hot-pressed samples of these materials are being exposed to sodium-containing combustion environments to assess their corrosion resistance. Chemical vapor deposition processes will then be developed for the most promising materials.

The starting materials for all hot-pressed samples are high purity powders which are combined and ball milled for $24 \mathrm{~h}$. The mixtures are then loaded into $38 \mathrm{~mm}$-diam graphite dies, and hot-pressed using appropriate conditions for each composition. Powder X-ray diffraction of each sample verified the material to be the compound of interest.

Processes for the chemical vapor deposition of $\mathrm{Ta}_{2} \mathrm{O}_{5}$ have already been developed at this laboratory. The system consists of an inductively heated substrate within a quartz tube sealed on each end by threaded stainless steel end caps. Chlorine and argon gas are introduced into a tantalum chlorinator electrically heated to $600^{\circ} \mathrm{C}$. $\mathrm{TaCl}_{5}$ exiting the chlorinator is mixed with oxygen flowing through a separate inlet tube. The deposition temperature $\left(1100-1300^{\circ} \mathrm{C}\right)$ is measured by an optical pyrometer sighting through a window in the end cap directly on the substrate. $\mathrm{Ta}_{2} \mathrm{O}_{5}$ coatings were applied to $\mathrm{SiC}$ coated graphite substrates to simulate a heat engine material system.

Corrosion tests are performed in a horizontal alumina tube furnace with an inner diameter of $60 \mathrm{~mm}$. Hot-pressed pellets of each material are sectioned and tested at $\approx 1000^{\circ} \mathrm{C}$. A combustion environment is simulated by flowing methane into the furnace at $685 \mathrm{~cm}^{3} / \mathrm{min}$ along with air at $7,600 \mathrm{~cm}^{3} / \mathrm{min}$. The sodium level is controlled by the position, and hence the temperature, of the $\mathrm{Na}_{2} \mathrm{CO}_{3}$ source. Based on the measured weight loss of the $\mathrm{Na}_{2} \mathrm{CO}_{3}$ source, the sodium concentration in the system varied from 20 to $110 \mathrm{ppm}$. Sodium concentrations that are an order of magnitude lower and exposure times that are an order of magnitude higher are inore realistic for many combustion applications. The total amount of sodium that the samples were exposed to was therefore similar to that projected for many applications, thus the experimental results that have been obtained provide a reasonable basis for approximating the performance of these materials. The sodium levels, however, may have been subject to some variation during each run, primarily because the exposed surface area of the sodium carbonate powder was not constant. 


\section{CORROSION TESTING}

Specimens of $\mathrm{Al}_{2} \mathrm{TiO}_{5}, \mathrm{ZrTiO}_{4}$, and $3 \mathrm{Al}_{2} \mathrm{O}_{3} \cdot 2 \mathrm{SiO}_{2}$ were successfully hot pressed for corrosion testing. Evaluation of these materials by $\mathrm{X}$-ray diffraction revealed that the desired crystalline compounds had been produced. The initial hot-pressing conditions selected for the $\mathrm{Al}_{2} \mathrm{TiO}_{5}$ produced a porous pellet, therefore, a dense specimen was obtained from a commercial source. $\mathrm{X}$-ray diffraction of the commercial material showed that the outer surface was predominantly $\mathrm{Al}_{2} \mathrm{O}_{3}$, whereas the interior of the pellet was $\mathrm{Al}_{2} \mathrm{TiO}_{5}$. The hot-pressed pellets of $\mathrm{ZrTiO}_{4}$ and $3 \mathrm{Al}_{2} \mathrm{O}_{3} \cdot 2 \mathrm{SiO}$ were fine grained, but the former contained approximately $20 \%$ porosity.

After exposing each of the candidate materials plus a sintered $\alpha$-SiC specimen to a combustion environment at $1000^{\circ} \mathrm{C}$, the pellets were examined metallographically. The $\alpha-\mathrm{SiC}$ had a surface layer of glass about $20 \mu \mathrm{m}$ thick. Significantly better corrosion resistance, which is consistent with the published results of Federer [4], was exhibited by $3 \mathrm{Al}_{2} \mathrm{O}_{3} \cdot 2 \mathrm{SiO}_{2}$ which had a $10 \mu \mathrm{m}$ glass layer. Further improvements in corrosion resistance are seen by $\mathrm{ZrTiO}_{4}$ and $\mathrm{Al}_{2} \mathrm{TiO}_{5}$ since the reaction layers were $\approx 4 \mu \mathrm{m}$ and $<2 \mu \mathrm{m}$ thick, respectively: $\mathrm{Al}_{2} \mathrm{O}_{3}$ grains were observed on the surface of the polished $\mathrm{Al}_{2} \mathrm{TiO}_{5}$ sample, thus verifying the $\mathrm{X}$-ray diffraction results discussed previously.

SiC-coated graphite substrates overcoated with $\mathrm{Ta}_{2} \mathrm{O}_{5}$ were also corrosion tested. During coating in an oxidizing environment, the $\mathrm{SiC}$ formed a relatively thick crystalline $\mathrm{SiO}_{2}$ protective layer. The $\mathrm{Ta}_{2} \mathrm{O}_{5}$ coating nucleated onto the $\mathrm{SiO}_{2}$ with small equiaxed grains that grew into large columnar ones normal to the surface (Fig. 3). Corrosion testing left the $\mathrm{Ta}_{2} \mathrm{O}_{5}$ coating and the crystalline $\mathrm{SiO}_{2}$ sublayer unaffected.

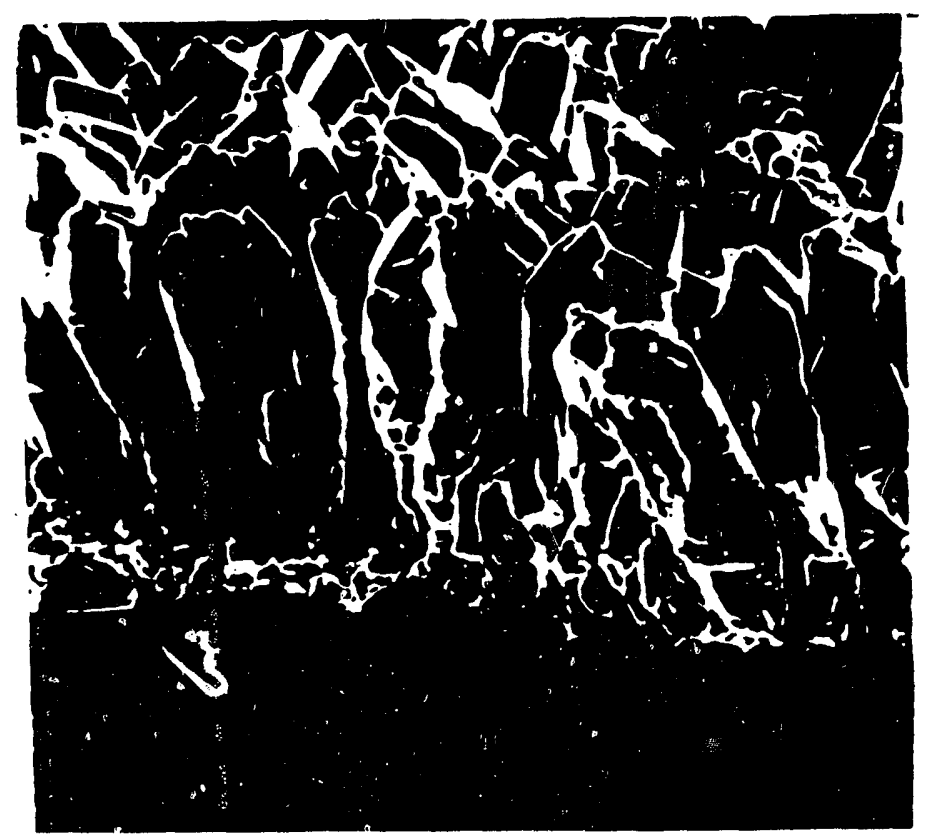

Figure 3. Fracture surface of a $\mathrm{Ta}_{2} \mathrm{O}_{5}$ coated substrate after corrosion testing.

Successful hot-pressing conditions have not yet been determined for $\mathrm{HfTiO}_{4}$, $\mathrm{Ta}_{2} \mathrm{O}_{5} \cdot 6 \mathrm{ZrO}_{2}$ and $\mathrm{Ta}_{2} \mathrm{O}_{5} \bullet 6 \mathrm{HfO}_{2}$. Analysis of the pellets produced to date by $\mathrm{X}$-ray diffraction have indicated unidentified phases. Additional process development will be required before corrosion testing can be initiated. 


\section{CONCLUSIONS}

Corrosion testing of various oxides revealed a considerable improvement over SiC. Mullite exhibited a glass reaction layer that was only about half as thick as the layer formed on a $\mathrm{SiC}$ specimen. Still better corrosion resistance was exhibited by $\mathrm{Al}_{2} \mathrm{TiO}_{5}$ and $\mathrm{ZrTiO}_{4}$. Chemically vapor deposited $\mathrm{Ta}_{2} \mathrm{O}_{5}$ exhibited excellent corrosion resistance. Further tests of much longer duration will be required to identify the most corrosion resistant oxides for overcoating $\mathrm{SiC}$ or $\mathrm{Si}_{3} \mathrm{~N}_{4}$ components. After the most promising materials have been identified chemical vapor deposition processes will be developed for application of coatings.

\section{ACKNOWLEDGEMENTS}

The authors are indebted to J. I. Federer whose interest and valuable suggestions helped carry this work to completion. Research sponsored by the U.S. Department of Energy, Assistant Secretary for Conservation and Renewable Energy, Office of Transportation Technologies, as part of the Ceramic Technology Project of the Materials Development Program, under contract DE-AC05-84OR21400 with Martin Marietta Energy Systems, Inc.

\section{REFERENCES}

1. J. L. Smialek and N. S. Jacobson, Mechanism of Strength Degradation for Hot Corrosion of $\alpha$-SiC. J. Am. Ceram. Soc. 1986, 69(10), 741-52.

2. N. S. Jacobson and D. S. Fox, Molten-Salt Corrosion of Silicon Nitride: II, Sodium Sulfate. J. Am. Ceram. Soc., 1988, 71(2), 128-48.

3. N. S. Jacobson, J. L. Smialek, and D. S. Fox, Molten Salt Corrosion of $\mathrm{SiC}$ and $\mathrm{Si}_{3} \mathrm{~N}_{4}$. In Handbook of Ceramics and Composites, Vol.1: Synthesis and Properties, ed. N. P. Cheremisinoff, Marcel Dekker, Inc. New York, 1990, pp. 99-136.

4. J. I. Federer, Corrosion of SiC Ceramics by $\mathrm{Na}_{2} \mathrm{SO}_{4}$. Adv. Ceram. Mater. 1988, 3(1), 56-61.

5. J. A. Costello and R. E. Tressler, Oxidation Kinetics of Hot-Pressed and Sintered $\alpha$-SiC. J. Am. Ceram. Soc. 1981, 64, 327-31.

6. N. S. Jacobson and J. L. Smialek, Hot Corrosion of Sintered $\alpha-\mathrm{SiC}$ at $1000^{\circ} \mathrm{C}$. J. Am. Ceram. Soc., 1985, 68, 432-39.

7. N. S. Jacobson, C. A. Stearns, and J. L. Smialek, Burner Rig Corrosion of SiC at $1000^{\circ}$ C. Adv. Ceram. Mater., 1986, 1, 154-61.

8. E. M. Levin, C. R. Robbins, H. F. McMurdie, Phase Diagrams for Ceramists, Vol. I, The American Ceramic Society, Westerville, OH, 1964, p.94. 
9. V. K. Sarin, Design Criteria for a Coating to Reduce Contact Stress Damage. In Proceedings of the 1987 Coatings for Advanced Heat Engines Workshop, Castine, ME, July 27-30, 1987, U.S. Department of Energy Report, Conf-870762, Page III-83.

10. H. E. Rebenne and V. K. Sarin, Ceramic Coatings to Reduce Contact Stress Damage of Ceramics: Thermodynamic Modeling. In Proc. 25th Automotive Technology Development Contractors' Coordination Meeting, Society of Automotive Engineers, Inc. Warrendale, Penn., 1988, P-209, pp. 199-206.

11. H. E. Rebenne and J. H. Selverian, Adherent Ceramic Coatings To Reduce Contact Stress Damage of Ceramics. In Proc. of the Annual Automotive Technology Development Contractors' Coordination Meeting, Society of Automotive Engineers, Inc. Warrendale, Penn., 1991, P-243, pp. 227-38.

12. M. A. Alvin, D. M. Bachovchin, J. E. Lane, and R. E. Tressler, Degradation of Cross Flow Filter Material. In Proc. of the Seventh Annual Coal-Fueled Heat Engines and Gas Stream Cleanup Systems Contractors Review Meeting Report No. DOE/METC90/6110, ed. H. A. Webb, et al., U. S. Department of Energy, Morgantown, W.Va., 1990, pp. 162-67.

13. I. Y. Glatter, D. J. Treacy, J. E. Sheehan, and K. S. Mazdiyasni, High-Temperature Chemical Behavior of a Multi-Layered Oxidation Protection Coating System for Carbon-Carbon Composites, Wright Research Development Center Report No. WRDC-TR-89-4127, 1989.

14. R. Ruh, et. al., Phase Relations and Thermal Expansion in the System $\mathrm{HfO}_{2}-\mathrm{TiO}_{2}$. J. Am. Ceram. Soc. 1976, $59(11-12)$ 495-99.

15. K. S. Mazdiyasni and L. M. Brown, Preparation and Characterization of High-Purity $\mathrm{HfTiO}_{4}$. J. Am. Ceram. Soc. 1970, 53(11), 585-89.

16. E. M. Levin and H. F. McMurdie, Phase Diagrams for Ceramists, 1975 Supplement, The American Ceramic Society, Westerville, OH, 1964, p. 169.

17. T. Takahashi and H. Itoh, Formation of Tantalum Oxide by Chemical Vapor Deposition. J. of Less-Common Metals, 1972, 38, 211-19.

18. E. Kaplan, M. Balog, and D. Frohman-Bentchkowsky, Chemical Vapor Deposition of Tantalum Pentoxide Films for Metal-Insulator-Semiconductor Devices. J. Electrochem. Soc.: Solid-State Science and Technology 1976, 123(10) 1570-73.

19. E. M. Levin and H. F. McMurdie, Phase Diagrams for Ceramists, 1975 Supplement, The American Ceramic Society, Westerville, OH, 1964, p. 92.

20. E. Parsons, Morgantown Energy Technology Center, Morgantown, WV., personal communication to D. P. Stinton, August 1990. 

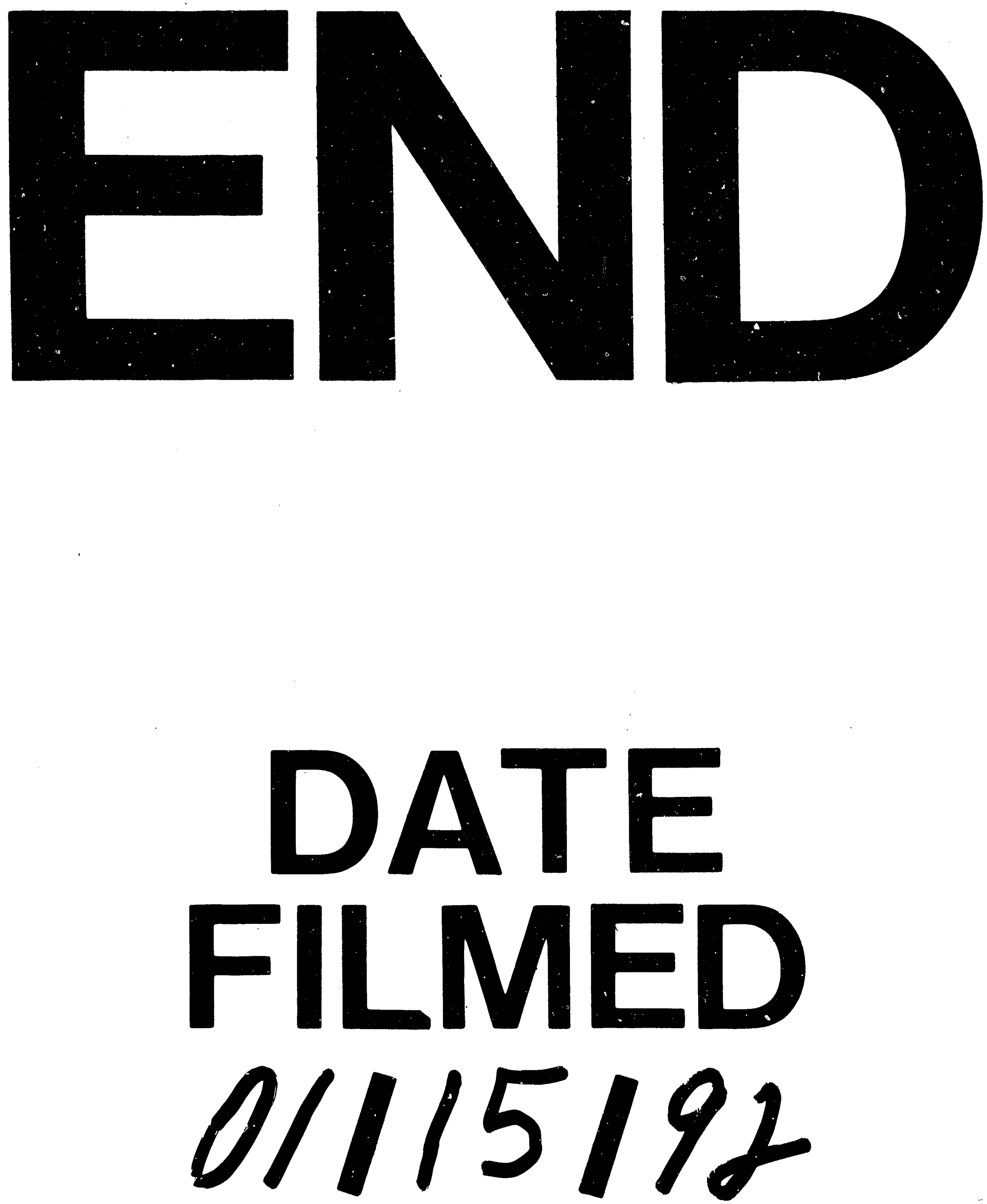
. M ' I ' 